\title{
Símbolo de la Odontología Maya
}

\author{
Symbol of Maya Dentistry
}

\author{
Rodrigo Villalobos Jiménez*
}

El símbolo que identifica nacional e internacionalmente a la odontología mexicana, fue inicialmente descrito por el Dr. Samuel Fastlicht, quien lo observó en un fragmento del mural policromado conocido como «El paraíso terrenal» de Tepantitla, en Teotihuacán y que probablemente representa la acción de limar los dientes, por parte de un chamán-odontólogo; es una imagen que ha sido ampliamente difundida.

En otro contexto, con distinta ubicación de tiempo y espacio, asociado con una cultura diferente a la teotihuacana, analizamos en este editorial, un antiguo símbolo de la Odontología Maya.

Entre los grandes tesoros que se hallan en el Museo del Jade, ubicado en el edificio del Instituto Nacional de Seguros de San José, Costa Rica en Centroamérica, se encuentra una magnífica pieza de arte precolombino; un colgante elaborado, en jade serpentina con grabados de escritura maya.

Fue descrito por el renombrado arqueólogo, epigrafista y etnógrafo británico John Eric Thompson, de la Universidad de Cambridge y del mundialmente reconocido Field Museum de Historia Natural de Chicago, EUA. Se trataba de uno de los máximos expertos en culturas mayas de la primera mitad del siglo $X X$, quien es citado por don Luis Ferrero, ${ }^{1}$ quien muestra y describe la imagen de un colgante de jade, con glifos en cartucho y del cual dice textualmente: «El glifo de la izquierda se interpretó como «cara de murciélago»; el de la derecha fue llamado por J. Eric Thompson «glifo de dolor de muelas " e interpretado como un buitre con vendaje para amarrarlo a la luna». Como detalle se aclara que su procedencia es Bagaces, Guanacaste, en el pacífico norte de Costa Rica, en Centroamérica.

Una gran cantidad de investigadores ha trabajado arduamente por muchos años, confrontando el reto de descifrar las escrituras precolombinas mesoamericanas como la olmeca, zapoteca, epiolmeca, izapa, ñuiñe, mixteca, mexica y maya.

El punto de partida en tan portentosa tarea ha sido el texto «Relación de las cosas de Yucatán», del obispo Fray Diego de Landa, quien fue inquisidor general y destruyó gran parte del legado cultural prehispánico en la hoguera, pero que efectuó un detallado relato de cómo era la región desde el año de 1549 hasta 1579, elaborando una descripción general de la vida entre los indígenas de esa época; además realizó dibujos de las estructuras lingüísticas de escritura, que fueron la base del futuro proceso de desciframiento de la escritura maya.

El etnógrafo mayista ucraniano Yuri Knórozov, de la Universidad de Moscú, desempeñó un papel fundamental en el desciframiento de la escritura maya. En 1952 publicó un texto titulado «Drevniaia Pis mennost Tsentralnoi Amerika» («Antigua escritura de Centroamérica»), donde sustentaba que el llamado «alfabeto de Landa» se componía de sílabas más que de símbolos alfabéticos. El mismo Knórozov mejoró su técnica de desciframiento en la monografía de 1963 "The writing of the Maya Indians" y publicó traducciones de manuscritos mayas en su obra de 1975 «Maya hieroglyphic manuscripts». En la década de 1960 los progresos revelaron los registros dinásticos de los gobernantes mayas. Fue a inicios de la década de 1980 cuando se demostró que la mayor parte de los símbolos anteriormente desconocidos, forman un silabario y desde entonces el avance en la interpretación de la escritura maya tomó mayor auge.

La rivalidad política en el marco de la Guerra Fría, entre Thompson y Knórozov, además de las diferencias de enfoque filosófico y práctico de la interpretación de los glifos, ya que Thompson hacia énfasis en la interpretación de imágenes y Knórozov en un enfoque silábico, fueron dirimidas con un inteligente punto intermedio por la famosa ilustradora, epigrafista y arqueóloga rusa de origen siberiano, que se desarrolló académicamente en EUA, Tatiana Proskouriakoff; ella dedujo que la escritura maya está compuesta por:

\footnotetext{
* Decano de la Facultad de Odontología de la Universidad Latina de Costa Rica.
}

Este artículo puede ser consultado en versión completa en http://www.medigraphic.com/facultadodontologiaunam 
- Signos fonéticos basados en sílabas.

- Ideogramas o logogramas que representan conceptos.

- Determinativos o morfemas que modifican el sentido de una palabra.

Proskouriakoff efectuó una minuciosa y correcta interpretación de innumerables estelas y escritos mayas, proponiendo una relación con retratos de los gobernantes y crónicas ubicadas en el tiempo del calendario maya, con relatos de las inscripciones y reportes literales de hechos concretos, con secuencias cronológicas y ubicación espacial del desarrollo de la cultura maya en variados lugares. En su libro «Maya history", editado por la University of Texas, Austin de 1993, ISBN 0-292-76600-9 en las páginas 44 y 45, precisa la expresión "bloodletting» (para nosotros equivale a la figura de la izquierda en el glifo presente en el Museo del Jade en Costa Rica, que Thompson había llamado el «hombre murciélago»), una imagen similar está presente en estelas ubicadas en la Gran Plaza de Copán, Honduras (Figura 1).

Citando a Harri Kettunen y a Christophe Helmke, quienes escribieron su libro «Introducción a los jeroglíficos mayas", en idioma inglés y que fueron traducidos al español por Verónica Amellali Vázquez López y por Juan Ignacio Cases Martín, en el año 2010, páginas 89 y 133: "Por lo general, un MORFEMA dependiente (ligado) que se puede agregar a un TEMA

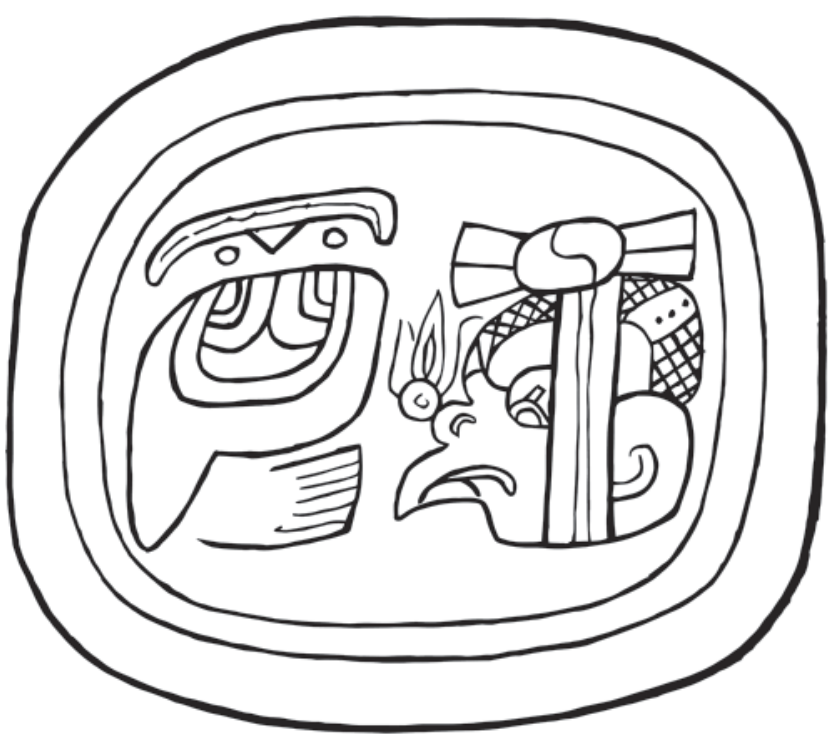

Autor: Dr. Silvia Villalobos Sancho.

Figura 1. Dibujo elaborado en tinta china, partiendo de la imagen original. o RAÍZ, para formar una palabra compleja y diferente (ejemplo, en «inutilizable», el prefijo es in- y el sufijo es ble-). En la escritura maya, los afijos también pueden funcionar como complementos fonéticos o, en el caso de los infijos, como palabras completas. A diferencia de las convenciones estandarizadas de la lingüística, y debido a la naturaleza del sistema de escritura, en la epigrafía maya los afijos están subdivididos en prefijos (antes), superfijos (arriba), subfijos (abajo), postfijos (después) e infijos (adentro de)».

En este caso, el afijo pronominal personal/posesivo es: u- u- «él, ella, eso, su» (antes de consonantes y vocales).

Traduciendo del inglés «bloodletting», como «sangría» y con la adición del afijo u, se podría interpretar como: «el que produce sangría».

Proskouriakoff también hace referencia en su libro al glifo del «toothache», presente en una estela de la ciudad maya de Piedras Negras, ubicada al oeste del Petén en la Sierra Lacandón, Guatemala, donde se representa el glifo del dolor de muelas, y se asocia con la ascensión al poder de un gobernante. También puntualiza que está presente en el sitio arqueológico de Yaxchilán, ubicado en Chiapas, México, como la ascensión del Rey Jaguar.

John Montgomery en su "Dictionary of Maya hieroglyphs", segunda edición del año 2006, de Hippocrene Books New York, ISBN 0-7818-0862-6, página 119, presenta y traduce el glifo del dolor de muela como «ascensión», «emerger», y confirma así el uso del nombre del «Glifo del dolor de muela», para eventos importantes.

En la tradición cultural de La Gran Nicoya basada en la etnia chorotega-mangue, con una visión que se podría generalizar al resto de Mesoamérica, el chamán era capaz de transformarse en el animal que fuera necesario para ejercer su función en el ritual mágico-religioso como influencia del nahualismo, en los que generalmente utilizaba ornamentos de jade, pieles de animales, plumas de aves y máscaras. El jaguar, el murciélago, el cocodrilo, la serpiente y la guacamaya, se consideraban animales sagrados en la tradición religiosa de los nicoyas.

Hay estrecha asociación entre el jade y los usos mágico-medicinales, por ejemplo: la nefrita que es la otra variedad de jade, junto a la jadeíta y de la cual no hay fuentes en Mesoamérica, deriva su nombre de «piedra de riñón», nombre dado por los antiguos romanos en Europa, atinente a la nefrología (nefrita) y que se supone los indígenas utilizaban como amuleto contra enfermedades del riñón, por sus propiedades curativas.

En la antigua pieza de jade serpentina (Figura 2), que estamos analizando se puede apreciar que: 


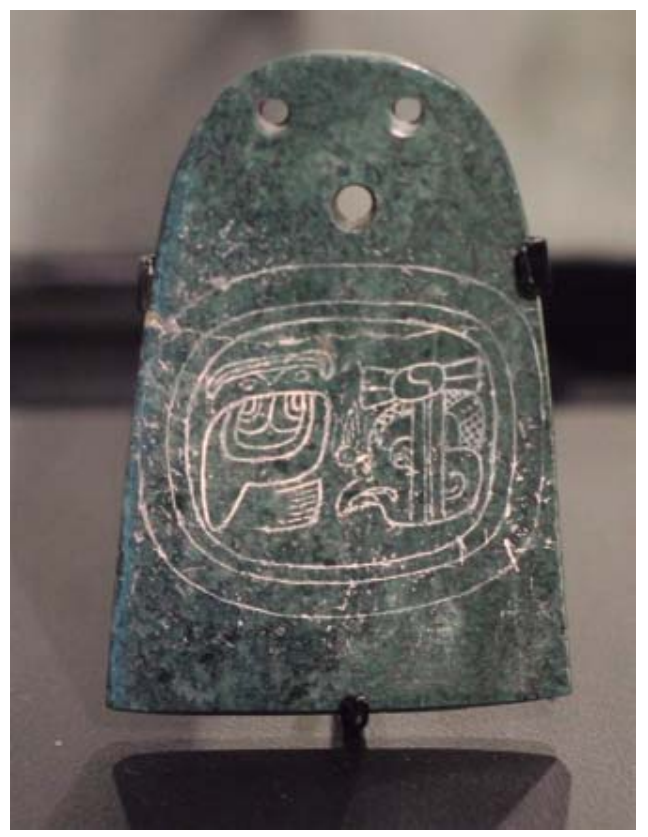

Autor: Rodrigo Villalobos Jiménez.

Figura 2. Fotografía de la pieza de jade.

- El glifo está englobado en tres círculos que definen una asociación directa entre ambas imágenes: chamán-odontólogo y su paciente.

- Thompson describe la imagen de la izquierda como el hombre-murciélago, Proskouriakoff traduce como el que produce sangría; bien podría considerarse que una posible interpretación es la de un chamán, que extiende su mano hacia el paciente, además posee una expresión facial positiva, casi amigable.

- La imagen de la derecha es descrita como «un buitre con vendaje anudado en la cabeza» y es el glifo del dolor de muela, un paciente cuya figura posee expresión facial de congoja o dolor.

- Se puede apreciar entre ambos jeroglíficos y cerca de la cara del paciente, la representación parcial de una flor o de unos pétalos, que bien podrían ser de una planta medicinal, para el tratamiento odontológico como sedante-analgésico-narcótico. Hay gran cantidad de plantas medicinales con alcaloides muy activos en Mesoamérica y gran tradición en sus aplicaciones por parte de la población.

- La pieza de jade posee tres perforaciones y se valúa su uso como un colgante posiblemente para el cuello, que podría anunciar las cualidades de la persona que lo portase.

Debe considerarse la posibilidad de que el glifo en esta imagen, sea la eventual representación de un an- tiquísimo proceso de atención dental, ya que existe extensa evidencia de múltiples tratamientos dentales, desgastes, «mutilaciones» y restauraciones dentales en las culturas mesoamericanas. En todo el mundo maya, desde el sur de México, Guatemala, Honduras, Belice, El Salvador, Nicaragua, incluida la parte norte de Costa Rica, hay gran cantidad de evidencias tangibles en los museos, con restos óseos y dentales de los tratamientos que se efectuaban en las personas, con fines curativos, estéticos o de identificación jerárquica.

Citando el libro sagrado de los mayas, escrito en lenguaje quiché y que relata la creación del mundo, el Popol Vuh, se narra la historia de los gemelos prodigiosos Junajpu e Ixb'alanke, quienes atacan a su rival Wuqub' K'aqix con su cerbatana y le «dislocan la quijada». Luego los gemelos acompañan a sus abuelos que son chamanes/curanderos, los cuales se identifican como «los que poseen el oficio de sacar el gusano que causa el dolor de muelas" y éstos le ofrecen aliviar el dolor al herido. Wuqub' K'aqix manifiesta que «los dientes le duelen de día y de noche y no puede comer ni dormir».

Los «odontólogos» son descritos como de pelo canoso y cuerpo encorvado, el anciano llamado SaqiNimAk' y la anciana SaqiNimaTz'i', quienes manifiestan: "Andamos buscando trabajo pues somos curanderos y éstos son nuestros nietos y les damos de comer lo que conseguimos", además le ofrecen quitar el dolor "eliminando las muelas y poniendo otras en su lugar», lo que efectuaron colocando granos de maíz blanco en reposición de las piezas extraídas, perdiendo de este modo su brillo, poder y fuerza, lo que permitió a los gemelos vencer a su enemigo, según la voluntad de Corazón del Cielo, que es el nombre dado a Dios en la cultura maya.

Hay también en el Popol Vuh referencias al uso de insignias, para identificar a las personas según su oficio y posición; considerando que esta pieza de jade posee tres perforaciones para ser colgada como collar, puede equipararse a los modernos rótulos luminosos que los odontólogos colgamos en los consultorios para anunciar y ofrecer servicios profesionales en salud oral; o al gafete de identificación que los odontólogos colocamos en la gabacha, para identificarnos en el hospital o la universidad.

Hay múltiples interrogantes a las cuales aún no se les ha dado respuesta, ¿habrá alguna relación entre el símbolo de la odontología mexicana de Teotihuacán y el de la odontología maya en Costa Rica?

Por el momento, mientras ésta y muchas otras preguntas se responden, queda la satisfacción de resaltar que la Odontología mesoamericana y a nivel global, encuentra en esta representación artística, elaborada 
con fino detalle, delicadamente trabajada sin herramientas modernas y todo esto realizado sobre una superficie de extrema dureza como la del jade, el trabajo de un consagrado artista maestro artesano del cual no poseemos su nombre, pero sí podemos reconocer su habilidad y destreza; es una imagen ancestral, que señala y resalta el ejercicio de una profesión dedicada a resolver situaciones de salud oral, que desde tiempos inmemoriales aquejan a la humanidad.

\section{REFERENCIAS}

1. Ferrero L. Costa Rica precolombina. Costa Rica: Editorial Costa Rica; 1979. p. 87.

\author{
Dirección para correspondencia: \\ Rodrigo Villalobos Jiménez \\ E-mail: rodrigovill@gmail.com
}

